\title{
Comparison of statistical and dynamical downscaling methods for seasonal scale winter precipitation predictions over North India
}

\author{
P.R. Tiwari ${ }^{1}$, S.C. Kar $^{2 *}$, U.C. Mohanty ${ }^{3}$, S. Dey ${ }^{4}$, P. Sinha ${ }^{5}$, M.S. Shekhar ${ }^{6}$ and R. S. Sokhi ${ }^{1}$ \\ ${ }^{1}$ Centre for Atmospheric and Climate Physics Research, Hatfield, United Kingdom \\ ${ }^{2}$ National Centre for Medium Range Weather Forecasting, Noida, India \\ ${ }^{3}$ School of Earth Ocean and Climate Sciences, IIT Bhubaneswar, India \\ ${ }^{4}$ Centre for Atmospheric Sciences, IIT Delhi, India \\ ${ }^{5}$ Indiana State Climate Office, Purdue University, USA \\ ${ }^{6}$ Snow and Avalanche Study Establishment, Chandigarh, India
}

\begin{abstract}
*Correspondence
Dr. S.C. Kar

National Centre for Medium Range Weather Forecasting (NCMRWF),

A-50, Sector-62, Noida, India

Email: sckar@ncmrwf.gov.in
\end{abstract}

\section{Abstract}

The main aim of the present study is to analyze the capabilities of two downscaling approaches (statistical and dynamical) in predicting wintertime seasonal precipitation over North India. For this purpose, a Canonical Correlation Analysis (CCA) based statistical downscaling approach and dynamical downscaling (at $30 \mathrm{~km}$ ) with an optimized configuration of the Regional Climate Model (RegCM) nested in coarse resolution global spectral model have been used for a period of 28 years (1982-2009). For CCA, nine predictors (precipitation, zonal and meridional winds at 850 and $200 \mathrm{hPa}$, temperature at $200 \mathrm{hPa}$ and sea surface temperatures) over 3 different domains were

This article has been accepted for publication and undergone full peer review but has not been through the copyediting, typesetting, pagination and proofreading process, which may lead to differences between this version and the Version of Record. Please cite this article as doi: $10.1002 /$ joc. 5897 
selected. The predictors were chosen based on the statistically significant teleconnection maps and physically based relationships between precipitation over the study region and meteorological variables. The validation revealed that both the downscaling approaches provided improved precipitation forecasts compared to the global model. Reasons for improved prediction by downscaling techniques have been examined. The improvement mainly comes due to better representation of orography, westerly moisture transport and vertical pressure velocity in the regional climate model. Further, two bias correction methods namely Quantile Mapping (QM) and Mean Bias-remove (MBR) have been applied on downscaled RegCM, statistically downscaled CCA as well as the global model products. It was found that when the QM based bias correction is applied on dynamically downscaled RegCM products, it has better skill in predicting wintertime precipitation over the study region compared to the CCA based statistical downscaling. Overall, the results indicate that the QM based bias corrected downscaled RegCM model is a useful tool for wintertime seasonal scale precipitation prediction over North India.

Key words: North India, winter precipitation, downscaling, CCA, RegCM, bias correction.

\section{Introduction}

Precipitation during winter seasons in north India (NI) is very important for Rabi crops, particularly for wheat as it supplements the moisture and maintains low temperature for the development of the crops. This NI region (comprising of the Indian states of Punjab, Haryana in the plains and Jammu and Kashmir, Himachal Pradesh, Uttarakhand in the Himalayas) receives about $25 \%$ to $30 \%$ of the annual precipitation during winter seasons (Tiwari et al. 2016a). Most of the precipitation during winter over the mountainous regions of NI (western Himalayas) is in the form of snow which helps in maintenance of glaciers throughout the year. Snow and ice melt 
(during spring and summer seasons) in the Himalayas influences the water availability downstream in the major river basins of south Asia (Tiwari et al. 2016b). Thus, advance information of winter precipitation (in terms of seasonal mean or anomaly) is useful for agriculture, water management sectors and various other sectors. Moreover, there is a demand of skillful seasonal prediction of winter precipitation from the resource managers as well as the farming community in north India (Mohanty et al. 2018).

Seasonal prediction skill in the tropical region is driven by slowly varying boundary conditions such as sea surface temperatures, snow cover and soil wetness etc, therefore, should have higher skill than sub-seasonal or monthly prediction (Shukla et al. 2000). Although there has been considerable advancement in computing resources and representation of physical processes in General Circulation Model (GCM), the skill of GCMs is still not satisfactory in simulating the spatial and temporal variability of seasonal mean temperatures and precipitation over India (Kumar et al. 2005; Wang et al. 2005; Barnston et al. 2010; Tiwari et al. 2014 and Tiwari et al. 2016a). A contributing factor is the coarse spatial resolutions (average spatial resolution is $\sim 1.3^{\circ}$; Taylor et al. 2012) of these GCMs that are insufficient to correctly represent the regional processes, land surface distribution and topography (Tiwari et al. 2017). Moreover, there are inadequacies on how well the large-scale teleconnection patterns linking global forcing such as El Nino Southern Oscillation (ENSO) or North Atlantic/Arctic Oscillations (NAO/AO) with the regional climate are represented in global climate models. As a result, direct use of the GCMs products may not be useful in predicting seasonal precipitation distribution at a regional scale..

In order to overcome the spatial scale issue, two approaches namely statistical and dynamical downscaling techniques are mainly used to downscale the coarse resolution GCM products to get regional information at finer scale. Christensen et al. (2007), in the Fourth 
Assessment Report of the Intergovernmental Panel on Climate Change (IPCC, AR4) have assessed the performance of several downscaling techniques and suggested that downscaling techniques are also capable of improving the skill of the predictions at local-scale. Similar conclusions on the use of downscaling techniques are reported by Flato et al. (2012) in the IPCC AR5 assessment. Dynamical downscaling is based on nesting of high-resolution regional climate models (RCMs) to simulate finer scale physical processes consistent with large scale weather simulated by a GCM (Giorgi et al. 2001). Statistical downscaling approach uses statistical relationships between the regional climate and statistical characteristics of the GCM data (Wilby et al. 2004; Marun et al. 2010; Goodess et al. 2012; Sachindra et al. 2014a; 2014b; Ayar et al. 2015) and are grouped into three different categories namely perfect prognosis, model output statistics (MOS) and weather generators. Sachindra et al. (2012) have reported that while dynamic downscaling approach is based on the use of complex physics of atmospheric processes and involves high computational costs, statistical downscaling is computationally less expensive. These reports further encourage to use the downscaling approaches for prediction of local/regional scale climate, however, both the techniques have some advantages and limitations. The canonical correlation analysis (CCA) technique is very popular amongst the MOS techniques due to its ease in implementation and interpretation. However, this linear technique does not represent the nonlinearity in the relationship between predictors and predictands. A comparison of linear and nonlinear artificial neural network (ANN) models by (Trigo and Palutikof, 2001) for downscaling of monthly precipitation over Iberia had shown that the linear ANNs had better skill. Moreover, Ramirez et al. (2006) have reported that when the predictor-predictand relationship is nonlinear, or when the predictand is non-Gaussian (e.g daily precipitation) ANNs have an advantage over standard parametric approaches. Therefore, superiority of any non-linear statistical downscaling 
method over the canonical correlation analysis method has not yet been established for downscaling monthly mean precipitation.

In last few years, many efforts (Sinha et al. 2013a; Sachindra et al. 2014b; Ayar et al. 2015) have been made using statistical downscaling techniques to predict regional precipitation at monthly as well as seasonal timescale. In all the studies, a clear improvement in precipitation prediction compared to parent GCM was obtained. On the other hand, studies using dynamical downscaling approaches (Sinha et al. 2013b, Tiwari et al. 2016b; Sorland et al. 2018) have also emphasized that the dynamical downscaling approach has potential to reproduce finer scale information with higher skill than the parent GCMs. A recent study conducted by Sorland et al. (2018) has shown that the regional climate models have systematically reduced the bias over the Alps and other regions of Europe. Further, these models are able to modify the climate change signals obtained from the driving GCMs, even on the scales that are considered well resolved by the driving GCMs.

Further studies (e.g. by Schmidli et al. 2007; Su et al. 2017; Grigory et al. 2018) have been carried out to compare dynamical and statistical downscaling methods over different regions worldwide. Schmidli et al. (2007) have used statistical and dynamical methods over European Alps region and stated that performance of these methods varies significantly from region to region and season to season. Su et al. (2017) have compared the monthly rainfall generated from statistical and dynamical methods over Heihe River Basin in China and reported that the skill of these two methods of downscaling varied from month to month. Recently Grigory et al. (2018) have applied statistical and dynamical downscaling methods and assessed their utility to provide seasonal forecast (June-September) for impact modelling in eastern Africa. The study reports that where dynamical downscaling method is able to reproduce the predictive signal evident in the 
has 80 waves in Triangular truncation equivalent to $1.4^{\circ} \times 1.4^{\circ}(\sim 150 \mathrm{~km})$ horizontal grid resolution. Further details about the model are provided in Kar (2007) and Kar et al. (2011). The model is initialized in November and integrated until the end of February for each year over the period 1982 to 2009. The 10 member ensembles are generated using the initial conditions from 110 November (total 10 different days) of each year, and for each initial date. The NCEP Climate Forecast System version 2 (CFSv2; 126 waves in Triangular truncation equivalent to $0.9^{\circ} \times 0.9^{\circ}$, $\sim 100 \mathrm{~km}$ horizontal grid resolution)) forecasted SST (Saha et al. 2014) is provided to the model as boundary condition. The regional climate model used in the present study is the International Centre for Theoretical Physics (ICTP) Regional Climate Model (RegCM4, version 4.1.1). More details of the model can be found in Elguindi et al. (2011) and Giorgi et al. (2012). The configuration of the RegCM used in the present study has been optimized for the domain of interest in a previous study by Tiwari et al. (2016b). For dynamical downscaling, the T80 model products at 12 hourly intervals are provided as the input to RegCM.

\subsection{Data used}

In this study ensemble mean of 10 members of the T80 model outputs for the period 19822009 are considered for statistical downscaling approaches. The observed SST (Smith et al. 2008) and ERA-Interim reanalysis (Dee et al. 2011) for the period 1982-2009 are used to examine observed teleconnection patterns. Observed daily rainfall data at $0.25^{\circ} \times 0.25^{\circ}$ resolution (Pai et al. 2014) obtained from India Meteorological Department (IMD) and station data sets from Snow Avalanche Establishment (SASE) has been used for validation purpose.

\subsection{Technique}

As mentioned earlier, so far, no statistical downscaling approaches using CCA have been developed for predicting wintertime precipitation over northern India. In the present study, the 
model output statistics approach is the CCA based on Wilks (1995). This CCA technique considers two multivariate datasets and selects a sequence of pairs of patterns. The original data are then projected onto these patterns and sets of transferred variables are constructed. The technique is elaborated further in the next paragraph.

In the $\mathrm{CCA}$ technique, the original data $\mathrm{P}$ (independent) and $\mathrm{Q}$ (dependent) are transformed into a new set of variables $X_{m}$ and $Y_{m}$ respectively, called canonical variables (Wilks, 1995). Here, P's are the predictor variables from the global model and Q is the predictant (observed precipitation data).

The canonical variables are defined as:

$$
\begin{aligned}
& X_{m}=A \times P \\
& Y_{m}=B \times Q
\end{aligned}
$$

The calculation of canonical vectors (A and $\mathbf{B}$ ) is similar to that of Principal Component Analysis (PCA). The linear regression between the canonical variables can be written as:

$$
Y_{m}=x X_{m}
$$

It can be easily proved that $=\mathbf{T}_{\mathrm{c}}$, where $\mathbf{T}_{\mathrm{c}}$, is the diagonal matrix of the canonical correlations. The original data $\mathrm{Y}$ can be easily estimated using the relation $\mathrm{Q}=\mathrm{B}-{ }^{1} \mathrm{Y}_{\mathrm{m}} \mathrm{B}$. Further details of the CCA methodology can be found in Singh et al. (2012) and Sinha et al. (2013).

Observations as well as model output data for the period from 1982-2009 are averaged from December to February for each month to get monthly values. From these monthly values, seasonal mean (DJF) values are also computed. Model precipitation fields were bi-linearly interpolated to the observed grid. Application of any other interpolation method (such as spline) did not provide any different output. The model precipitation outside the Indian region are not considered in the present study. 
Two bias correction methods (i) quantile mapping (QM) and (ii) mean bias correction (MBR) described in Tiwari et al (2016b) have been used in the present study. The bias corrections have been applied to monthly mean precipitation predictions from the T80 model, the RegCM model and the CCA model before making seasonal mean. Based on the observed data few wet years $(1991-92,1994-95,1995-96,1997-98)$ and dry years $(1984-85,1996-97,2000-01,2008-09)$ were selected for more detailed analysis. For evaluation of the results, several skill metrics such as mean squared error, multiplicative bias, Kendall rank correlation coefficient, Wilmott's index of agreement (WIOA), percent error of prediction have been used. The Student $t$-test is used for statistical significance test of correlation and the critical value is 0.33 at $95 \%$ confidence level. The above mentioned skill metrics are briefly discussed below:

Mean squared error: It measures the mean squared difference between the forecasts (F) and observations $(\mathrm{O})$. The perfect score for this metric is 0 .

$$
M S E=\frac{1}{N} \sum_{i=1}^{N}\left(F_{i}-O_{i}\right)^{2}
$$

Multiplicative bias: This skill metric mainly represent the model's ability to simulate the observed climatology and it is defined as ratio of the climatology of predicted and observed climatology. The perfect score for this metric is 1 .

Kendall rank correlation coefficient: It is commonly referred as Kendall's tau and measures the association with the presumption that the predictor-predicted relationship may not be linear (Wilks 2006). This skill metric is considered more general and alternative to Pearson's correlation.

Willmott's index of agreement: Willmott (1982) proposed a skill metrics which is called 'Willmott's index of agreement (WIOA)' and it is defined as: 


$$
W I O A=1-\left[\frac{\sum_{i}\left(F_{i}-O_{i}\right)^{2}}{\sum_{i}\left(\left|F_{i}-\bar{O}\right|+\left|O_{i}-\bar{O}\right|\right)^{2}}\right]
$$

where $\mathrm{Fi}$ and $\mathrm{Oi}$ are the ith year forecast and observation respectively and $\mathrm{O}$ is the observed climatology. WIOA is bounded between 0 and $1(0 \leq \mathrm{WIOA} \leq 1)$ and the perfect score for this index is 1 .

Percent error of prediction (PE): Perez and Reyes (2001) suggested that a predictive model will be termed as good one if the PE is close to 0 . It is computed as:

$$
P E=\frac{\left\langle\mid F_{i}-O_{i}\right\rangle}{\left\langle O_{i}\right\rangle} \times 100
$$

where Oi and Fi denotes the observed and predicted values in the ith case and $<>$ implies the average over the whole test set.

\section{Application}

The techniques described in section 2.3 have been applied here and presented into three Segments namely i) the NCMRWF global model diagnosis, ii) model output statistics (MOS) approach for predicting wintertime (DJF) precipitation and, iii) comparison of dynamical (bias corrected downscaled RCM) and statistical downscaling. Before presenting the results related to the prediction of wintertime precipitation using statistical downscaling, the results of a brief diagnostic study of the NCMRWF (T80) model output are described.

\subsection{Global model diagnosis}

As the global T80 model simulated precipitation is provided as input to the statistical downscaling model, as a first step, salient features of the model simulated precipitation have been 
examined. As mentioned earlier, western disturbances (WD) propagating from west to east contribute to major part of precipitation during winter over the NI region. In order to study the precipitation characteristics, the longitudinal mean of precipitation (Hovmoller diagram) of available 26 years (1982-2007) from the observation and the T80 model are plotted in Figure 1 (a) and (b) respectively. It can be seen from Fig. 1 (a) that the maximum precipitation lies between the latitudinal belt of $32^{\circ} \mathrm{N}$ to $36^{\circ} \mathrm{N}$ for each year. The northern part of Kashmir receives maximum precipitation (2-7 $\mathrm{mm} /$ day) during winter and the precipitation amount reduces gradually southward. Figure 1 (b) indicates that the precipitation distribution is represented well in the model simulations, however the maximum precipitation belt is shifted towards south. Further, the model simulated precipitation amount is lower (by about $2 \mathrm{~mm} /$ day) than observed values in some years. Fig. 1 (C) has the bias between the model and observed precipitation. It is seen that the $\mathrm{T} 80$ model has dry bias mainly between $33^{\circ} \mathrm{N}$ to $36^{\circ} \mathrm{N}$. Interannual precipitation variability (standard deviation) at each grid point has been calculated from the observed and model simulated precipitation for the period of study (figure not shown). It is noticed that the interannual standard deviation is high over NI region and some pockets of North East India. The values of interannual standard deviation (ISD) over these regions range from 15 to $35 \mathrm{~mm}$. The highest ISD is found over the areas experiencing large amount of precipitation during winter that is the northern part of India in observation. The T80 global model is able to show the total variance of precipitation as in observation up to certain extent and the ISD values are less than $30 \mathrm{~mm}$ over NI region.

The spatial averages (NI region) of seasonal mean precipitation anomalies (based on baseline period 1982-2007) from the observed gridded data and the ensemble mean along with individual members of the T80 model forecasts are shown in Figure 2. It is seen from the figure that over the region of interest, maximum observed precipitation was in 1994 and minimum 
precipitation occurred in $2000(\sim 1 \mathrm{~mm} /$ day $)$. The T80 model generally produces less precipitation over NI region as compared to observed precipitation as discussed below. In 1994, observed precipitation during the season was more than $4 \mathrm{~mm} / \mathrm{day}$. However, the precipitation value from the T80 model is within $2 \mathrm{~mm} /$ day, indicating large bias in the model precipitation. Moreover, it is seen from the figure that interannual variability of the model-simulated precipitation does not agree with that of observed precipitation. Further it can be also noted that the model precipitation anomaly shows opposite sign compared with observations during the few extreme years such as 1996, 2000.

Figure 3 (a) and (b) show the correlation coefficient (CC) and normalized mean squared error (NMSE) between the model precipitation and observations respectively. It can be seen that the values of correlation coefficients for the T80 model over Northern parts of India are low and range from 0.3 to as low as -0.1 . For the number of years used this computations, correlation values greater than 0.33 are statistically significant at $95 \%$ confidence level. Therefore, the T80 model does not have statistically significant correlation skill for precipitation over the NI region during winter season. The NMSE values lies in between 0.5 to $2 \mathrm{~mm} /$ day over Jammu and Kashmir (J\&K) region of NI. Further the maximum value of NMSE can be see over the northwest Kashmir where it is about $2 \mathrm{~mm} /$ day.

This study reveals that the T80 model has a number of deficiencies in its predictions of the precipitation in terms of intensity and variability. Interannual variation as well as the flow pattern for extreme years in the model exhibit differences with that of the observations. Interannual variability of the model ensemble-mean precipitation depends on how the model responds to local and remote SST forcing prescribed in the model. The analysis of precipitation variability of the model presented so far indicates that the model may be incorrectly responding to prescribed SSTs. 
It also appears that the model precipitation over NI region is linked to the sea surface temperature over the Pacific and the Indian Ocean. This aspect is further examined in the next section while developing the CCA model. In the following, the potential for statistical downscaling of model output using CCA is explored to improve seasonal forecasts of wintertime precipitation over NI region.

\subsection{Wintertime precipitation prediction using MOS approach}

As mentioned earlier, Model Output Statistics (MOS) approach using the CCA technique has been used in this study. As a first step towards this, teleconnection maps have been prepared to find suitable predictors as well as domains and, then predictions of wintertime (DJF) precipitation over NI region have been made using MOS. Monthly values from observation as well as the T80 model have been used to build the CCA model. Seasonal mean precipitation for each year has been computed from these monthly mean downscaled values.

\subsubsection{Teleconnection maps}

Precipitation over NI is largely influenced by several global forcing such as the ENSO, NAO and AO (Kar and Rana, 2013). Teleconnection maps are generated using the correlation between wintertime precipitation over NI and different meteorological parameters (surface as well as upper air) obtained from observations and the T80 model output separately for the period 1982-2007. For this, correlation maps between NI precipitation and global variables (meteorological parameters of surface and upper air) are produced at $95 \%$ confidence level. The analysis is performed separately using observed and model hindcast data respectively, and the correlation maps are drawn. Based on the teleconnection maps and physically based relationships between NI precipitation and meteorological variables, nine predictors out of which two are precipitation and 
meridional wind at $200 \mathrm{hPa}$ over the domain-1, four predictors (zonal wind at 850 and $200 \mathrm{hPa}$, meridional wind at $850 \mathrm{hPa}$ and temperature at $200 \mathrm{hPa}$ ) over the domain-2 and three predictors (zonal wind at 850 and 200hPa and SST) over domain-3 are considered for statistical downscaling from the T80 model using CCA. The anomaly correlation between wintertime precipitation over NI and different meteorological parameters (surface as well as upper air) obtained from observations and the T80 model output for the period 1982-2007 is shown in in Figure 4. Furthermore, the exact domains with their corresponding dimensions in latitude/longitude directions are shown in Figure 5. Since the length of the data period is moderate (26 years), only nine predictors have been chosen for the present study. The domain-1 covers the Indian region. Precipitation is the first automatic choice for the CCA model to predict precipitation. The meridional winds at $200 \mathrm{hPa}$ indicate the amplitude and zone of the westerly troughs over the study area which has strong relationship with precipitation variability in the region (Kar and Rana, 2014). The domain-2 covers the north Indian Ocean along with central and west Asia. Interannual variation of precipitation over north India is due to passage of western disturbances that originate in the Mediterranean Sea and Caspian Sea regions. Zonal and meridional winds at $850 \mathrm{hPa}$ and $200 \mathrm{hPa}$ and upper air temperature at $200 \mathrm{hPa}$ adequately represent the passage of these western disturbances. Moreover, the impact of the North Atlantic Oscillation and Arctic Oscillation are noticed in these variables. So there parameters get chosen for the CCA model. The domain-3 is the eastern and central Pacific region and indicates the ENSO through the seas surface temperature and zonal winds at $850 \mathrm{hPa}$ and $200 \mathrm{hPa}$. The relationship between precipitations over NI with that of ENSO has been described by Kar and rana (2014). Therefore, these 3 parameters have also been chosen for the CCA model

\subsubsection{Prediction of DJF precipitation}

This article is protected by copyright. All rights reserved. 
In this study, while developing the CCA model, data for 26 years (1982-2007) have been considered for training period to compute canonical variables and correlations for the regression equations. Various studies (Ayar et al. 2015; Tiwari et al. 2014; Sinha et al. 2013a) have suggested that when the data length is limited, cross validation approach is very useful. Therefore, in the present study, leave-three-out (one forecasted year and another two years randomly selected) cross-validation technique has been used for calculation of the canonical coefficients. The omission of the two random years in addition to the forecasted year was found to make the CCA model more robust and reduces the cross-validation bias (Mason and Tippett 2004, Sinha et al. 2013a). The anomaly correlation has been plotted in Figure 6 to understand the performance of the CCA model. It is seen that all predictors have reasonable skill in prediction of wintertime (DJF) precipitation over most parts of NI. However, reasonable skill of forecast using composite techniques is obtained over larger area than individual predictors. The number of grid points with skill more than $0.33 \mathrm{CC}$ is 62 for composite forecast which is the highest as compared to any individual predictor forecast (47 grid points is the maximum among individual predictor forecasts) or mean forecast (31 grid points exhibit more than $0.33 \mathrm{CC}$ ). Figure 6 also indicates that among all the predictor fields, the model precipitation over NI region has less potential than large-scale flow patterns in predicting wintertime (DJF) precipitation. This may be due to poor performance of the T80 model in predicting year-to-year precipitation variation as well as intensity over NI. It may be noted here that the correlation of the model precipitation (direct model output interpolated over observation grid) with observed precipitation is poor (statistically not significant) over NI region (Figure 3a) while, an improvement in skill is noticed with the use of CCA based statistical downscaling approach.

\subsection{Comparison of Statistical and dynamical downscaling approaches}


Evaluation of performance of both the statistical and dynamical downscaling approaches (forecast mode) has been made in predicting wintertime (DJF) precipitation over the NI region. For this purpose, model precipitation has been interpolated over IMD grid point and areas outside the Indian landmass are not considered. For dynamical downscaling, high-resolution (at $30 \mathrm{~km}$ ) simulations of RegCM4 (along with two bias corrected methods namely MBR and QM) have been considered. The bias correction methods are explained in Tiwari et al (2016b). In the case of statistical downscaling, composite forecast of wintertime (DJF) precipitation have been considered to compare both the dynamical and statistical downscaling approaches. Firstly a comparison for a period of 26 years (1982-2007) is made. A number of statistical skill metrics such as multiplicative bias, Kendall rank correlation coefficient, Wilmort's index of agreement (WIOA) and percentage error and prediction yield have been calculated and discussed below. Further, for better representation, the magnitude of all above stated skill metrics have been presented in Table 1 for the T80, CCA, RegCM and two bias corrected methods (MBR and QM) applied on T80 model (hereafter referred as T80_MBR and T80_QM), statistical downscaling based CCA model (hereafter referred as CCA_MBR and CCA_QM) and dynamical downscaled RCM (hereafter referred as RegCM_MBR and RegCM_QM) respectively.

\subsubsection{Multiplicative bias}

To comapre the climatology of the forecast with the climatology of observed precipitation, multiplicative bias has been computed and shown in Table 1. Esentially it represents the model's ability to simulate the climatology of observations and is defined as the ratio of the climatology of predicted and observed climatology. Efficiency of the prediction is considered to be maximum when this index is close to 1 . The Multiplicative bias of the T80, T80_MBR, T80_QM, CCA, CCA_MBR, CCA_QM, RegCM, RegCM_MBR and RegCM_QM is $0.49,0.51,0.54,0.67,0.69$, 
$0.76,0.58,0.72$ and 0.81 respectively.. The results clearly indicate that the QM based bias corrected downscaled RCM (i.e. RegCM_QM) is more efficient than CCA based statistical downscaling, bias corrected CCA (CCA_MBR and CCA_QM) and other methods to reproduce the observed precipitation climatology.

\subsubsection{Kendall rank correlation coefficient}

While the Pearson's correlation coefficient is a measure of linear association (i.e. it considers only linear relationship between the predicted and actual observation), the Kendall rank correlation coefficient (Kendall's tau), measures the association with a presumption that the predictor-predicted relationship may not be necessarly linear (Wilks 2006). This skill metric is considered to be more robust and in general an alternative to Pearson's correlation coefficient. The Kendall rank correlation coefficient (Kendall's tau) for the T80, T80_MBR, T80_QM, CCA, CCA_MBR, CCA_QM, RegCM, RegCM_MBR and RegCM_QM is computed (Table 1) and which are $0.21,0.24,0.29,0.33,0.36,0.41,0.30,0.37$ and 0.45 respectively. A two tailed Student t-test has been performed and it shows that the Kendall's tau for bias corrected dynamically

downscaled RCM has significant skill (significant at 95\% confidence level). Moreover, the advantages of QM based bias corrected downscaled RCM is also established in terms of Kendall's tau.

\subsubsection{Wilmott's index of agreement (WIOA)}

The above stated skill metrics have certain limitations as they are not bounded and are not suitable for very small (near zero) climatology of observation (Willmott 1982). Willmott index of agreement (WIOA) is bounded between 0 and $1(0 \leq \mathrm{WIOA} \leq 1)$. The closeness of this index to 1 indicates the efficiency of the model in producing a good forecast. The usefulness of such a metric in judging the precipitation predictions has been discussed in many studies (Chattopadhyay et al. 
2010; Acharya et al. 2013; Tiwari et al. 2014). In this study, the WIOA for the T80, T80_MBR, T80_QM, CCA, CCA_MBR, CCA_QM, RegCM, RegCM_MBR and RegCM_QM has been computed and shown in Table 1. The WIOA for the T80, T80_MBR, T80_QM, CCA, CCA_MBR, CCA_QM, RegCM, RegCM_MBR and RegCM_QM is 0.36, 0.39, 0.44, 0.55, 0.57, $0.63,0.51,0.64$ and 0.76 respectively. The result clearly indicates that bias corrected downscaled $\mathrm{RCM}$ has an edge over the RegCM and CCA based statistical downscaling in predicting witertime precipitation over NI region.

\subsubsection{Percentage error and prediction yield}

We have calculated percentage error for the T80, T80_MBR, T80_QM, CCA, CCA_MBR, CCA_QM, RegCM, RegCM_MBR and RegCM_QM. The average percentage error (averaged over 26 years) is $23.9,23.7,23.6,22.4,22.3,22.2,23.5,22.1$ and 21.7 respectively.. This further shows that the bias corrected downscaled RCM has an edge over the bias corrected CCA based statistical downscaling in predicting wintertime precipitation over NI region. The predicted yield for different error categories $(5,10,15$ and $20 \%$ error) as followed by Chattopadhyay et al. (2010) were also computed for the T80, T80_MBR, T80_QM, CCA, CCA_MBR, CCA_QM, RegCM, RegCM_MBR and RegCM_QM respectively as well. It is found that if we allow an error as small as $5 \%$, the predicted yields of the T80, T80_MBR, T80_QM, CCA, CCA_MBR, CCA_QM, RegCM, RegCM_MBR and RegCM_QM turns out to be 0.06, 0.073, 0.08, 0.12, $0.121,0.136,0.10,0.14$ and 0.18 respectively.. Further, if 10,15 , and $20 \%$ errors of prediction are allowed, then the prediction yields are $0.24,0.31$ and 0.51 respectively for RegCM_QM method. Furthermore, it can be noticed that the prediction yields by the T80, T80_MBR, T80_QM, CCA, CCA_MBR, CCA_QM, RegCM and RegCM_MBR methods for 10, 15, and $20 \%$ are less than the corresponding values in the case of RegCM_QM. For better understanding, the values of the 
prediction yields for different percentage error categories is presented in Fig. 7. The result clearly indicates that the QM based bias corrected downscaled RCM (RegCM_QM) has an edge over the bias corrected CCA model (CCA_QM) in predicting wintertime precipitation over the NI region.

Finally, the role of both downscaling approaces (CCA based statistical downscaling and two bias correction based dynamical downscaling methods) in prediction of magnitudes of precipitation anomalies for individual years (extreme years) has been examined. Forecasts for the NI region has been prepared independently for the year 2008 and 2009. In Figure 8, different bars (black, grey, cyan, sky-blue, dark-blue chocolate, green and gold) represents observed and predicted percentage departure of precipitation respectively. It can be noticed from the diagram that over the NI region for year 2008 the observed departure is $-17.2 \%$ while the predicted precipitation departure is $-8.9 \%,-9.1 \%,-10.4 \%,-13.7 \%,-12.9 \%$ and $-15.7 \%$ for the $\mathrm{T} 80$, T80_QM, CCA, CCA_QM, RegCM and RegCM_QM respectively. Similarly, in 2009, the predicted percentage departures are of the same sign but the magnitude is $23.8 \%, 9.5 \%, 10.1 \%$, $15.6 \%, 18.7 \%, 18.1 \%$ and $21.4 \%$ respectively for observation, T80, T80_QM, CCA, CCA_QM, RegCM and RegCM_QM. In conclusion, the QM based bias corrected downscaled RCM (i.e. RegCM_QM) is able to capture most of the observed features in the years 2008 and 2009 and has maximum skill followed by the CCA_QM based predictions.

From the above discussions, it is evident that the QM based bias corrected downscaled RCM (i.e. RegCM_QM) consistently outperforms other downscaling or bias correction methods. However, it may be noted that the quantile mapping procedure corrects the statistical moments and some statistical attributes of the cumulative distribution function (CDF) but it disrupts the temporal sequence Sachindra et al. 2014b. Improved time series data could be generated by employing monthly data for bias correction in the study of Sachindra et al. 2014b. Therefore, in 
this study, bias correction has been carried out using monthly data (of global model, RegCM and statistically downscaled). The quantile mapping bias correction has also been applied to the raw model data before downscaling. It is found that the seasonal mean precipitation time series data obtained after following this procedure has better skill as compared to other methods. Sachindra et al. 2014b have suggested the use of nested bias correction (NBC) method to overcome the disruption of time sequence when quantile mapping bias correction is applied. However, in this study, the NBC method has not been used and will be attempted in future studies.

\subsection{Comparison and validation of downscaled precipitation with station observations}

In the present section, both the downscaling approaces (CCA based statistical downscaling and QM based bias corrected dynamically downscaled RCM) along with the T80 global model are validated against the Snow and Avalanche Study Establishment (SASE), observations over seventeen stations located over the North Indian part of the Western Himalayas (IWH) region. The station-wise seasonal mean precipitation obtained from SASE observation, both the downscaling approaches and the T80 model is presented in Table 2 . The italic shaded values indicate the closest ones to the SASE observations. Further, for a better insight, the Phase synchronizing events (PSE) have been computed based on Table 2 results. More details of PSE computation can be found in Tiwari et al. (2016b). It is noticed from Table 2 that the PSE value is maximum (with 94\%) for composite (i.e., model output matches the sign of with observations $94 \%$ times) of wet minus dry years for QM method followed by CCA based statistical downscaling method (with 88\%), T80_RegCM (with 70\%) and T80 model (with 58\%). Therefore, it can be concluded that the QM based bias corrected dynamically downscaled RCM is able to represent the precipitation well compared to CCA based statistical downscaling, T80 driven RegCM and the T80 model.

\section{Conclusion}


Two downscaling approaches (CCA based statistical downscaling and dynamical downscaling using RegCM4 model) have been evaluated for wintertime (DJF) precipitation prediction over North India (NI) region. The NCMRWF global spectral model (T80) outputs have been used as input for both downscaling approaches. The major findings of this study are enumerated as follows:

- The global T80 model has a dry bias over North India during winter seasons. The simulated mean climatological precipitation amount as well as its interannual variation are less than that of observations.

- A CCA based model has been developed to statistically downscale the wintertime precipitation in seasonal timescale using the T80 model products. Based on the teleconnection maps and physically based relationships between NI winter precipitation and meteorological variables, nine predictors are considered for the CCA. The CCA method improves the forecast skill over some parts of NI. Further, the domain with higher correlations is more in case of composite forecast than the forecasts from individual predictors.

- A detailed comparison of CCA and bias corrected CCA model is made against bias corrected dynamical downscaled RCM for a period of 26 years (1982-2007). All the skill metrics clearly indicate that the CCA based statistical downscaling has higher skill compared to the RCM based dynamical downscaling and the T80 model. Further analysis suggests that the QM based bias corrected downscaled RCM has an edge over the CCA based statistical downscaling and bias corrected CCA model in predicting wintertime precipitation over the NI region. 
- The performance of both downscaling approaces in prediction of precipitation anomaly magnitudes for two extreme winter seasons has been examined. The result clearly indicates that the performances of both the downscaling techniques in representing the seasonal mean precipitation over the NI region are better than the GCM. Further, the QM based bias corrected downscaled RCM has maximum skill over the NI region.

This study has shown that both the downscaling techniques have the efficiency to improve the skill in predicting wintertime seasonal precipitation over the NI region. Both the techniques are able to correct the GCM forecasts of precipitation over the NI region. Finally, QM based bias corrected downscaled RCM has statistically better performance over RegCM and CCA based statistical downscaling and can be used as a seasonal prediction system in predicting witertime precipitation over the NI region.

\section{Acknowledgements}

We thank the anonymous reviewers for their comments and suggestions that helped in improving the earlier version of the manuscript. Authors sincerely acknowledge the India Meteorological Department (IMD) and Snow Avalanche Establishment (SASE) for providing their daily gridded and station-wise precipitation data. The authors would also like to acknowledge European Centre for Medium-Range Weather Forecasts (ECMWF) for making their ERA-Interim data available to this study. The first author's contribution to this work is supported by the ECR Program of the Centre for Atmospheric and Climate Physics Research at the University of Hertfordshire. The work is partly supported by research grant from Department of Science and Technology, Govt. of 
India under contract DST/CCP/PR/11/2011 through a research project operational at IIT Delhi (IITD/IRD/RP2580).

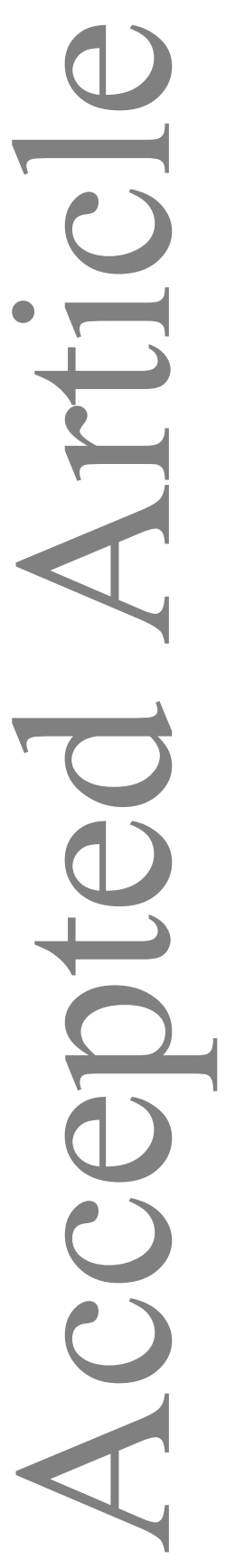




\section{References}

Acharya N, Chattopadhayay S, Mohanty UC, Dash SK, Sahoo LN. 2013. On the bias correction of general circulation model output for Indian summer monsoon. Met. Appl. 20: 349-356.

Ayar PV, Vrac M, Bastin S, Carreau J, Déqué M, Gallardo C. 2015. Intercomparison of statistical and dynamical downscaling models under the EURO- and MED-CORDEX initiative framework: present climate evaluations. Clim. Dyn. 46 (3): 1301-1329.

Barnston AG, Li S, Mason SJ, DeWitt DG, Goddard L, Gong X. 2010. Verification of the first 11 years of IRI's seasonal climate forecasts. J. Appl. Meteorol. Clim. 49: 493-520.

Chattopadhyay G, Chattopadhyay S, Jain R. 2010. Multivariate forecast of winter monsoon rainfall in India using SST anomaly as a predictor: neurocomputing and statistical approaches. Compt. Rend. Geosci. 342: 755-765.

Christensen JH, Hewitson B, Busuioc A, Chen A, Gao X, Held I, Jones R, Koli RK, Kwon W-T, Laprise R, Rueda VM, Mearns L, Menéndez CG, Räisänen J, Rinke A, Sarr A, Whetton P. 2007. Regional climate projections. In: Solomon S, Qin D, Manning M, Chen Z, Marquis M, Averyt KB, Tignor M, Miller HL (Eds.), Climate Change 2007: The Physical Science Basis. Contribution of Working Group I to the Fourth Assessment Report of the Intergovernmental Panel on Climate Change. Cambridge University Press, Cambridge, pp. 847-940.

Dee DP, Uppala SM, Simmons AJ, Berrisford P, Poli P, Kobayashi S, Andrae U, Balmaseda MA, Balsamo G, Bauer P, Bechtold P, Beljaars ACM, van de Berg L, Bidlot J, Bormann N, Delsol C, Dragani R, Fuentes M, Geer AJ, Haimberger L, Healy SB, Hersbach H, Hólm EV, Isaksen L, Kållberg P, Köhler M, Matricardi M, McNally AP, Monge-Sanz BM, Morcrette JJ, Park BK, Peubey C, de Rosnay P, Tavolato C, Thépaut JN, Vitart F. 2011. 
The ERA-Interim reanalysis: configuration and performance of the data assimilation system. Q. J. R. Meteorol. Soc. 137: 553-597.

Dutta SK, Das S, Kar SC, Mohanty UC, Joshi PC. 2009. Impact of vegetation on the simulation of seasonal monsoon rainfall over the Indian subcontinent using a regional model. J. Earth Syst. Sci. 118: 413-440.

Elguindi N, Bi XQ, Giorgi F, Nagarajan B, Pal J, Solmon F, Rauscher S, Zakey A, Giuliani G. 2011. Regional climatic model RegCM user manual version 4.1.1. The Abdus Salam International Centre for Theoretical Physics Strada Costiera, Trieste, Italy.

Flato G, Marotzke J, Abiodun B, Braconnot P, Chou SC, Collins W, Cox P, Driouech F, Emori S, Eyring V, Forest C, Gleckler P, Guilyardi E, Jakob C, Kattsov V, Reason C, Rummukainen M. 2013. Evaluation of climate models. In: Stocker TF, Qin D, Plattner GK, Tignor M, Allen SK, Boschung J, Nauels A, Xia Y, Bex V, Midgley PM (Eds.), Climate Change 2013: The Physical Science Basis. Contribution of Working Group I to the Fifth Assessment Report of the Intergovernmental Panel on Climate Change. Cambridge University Press, Cambridge, United Kingdom and New York, NY, U.S.

Giorgi F, Hewitson B, Christensen H, Hulme M, Von Storch H, Whetton P, Jones R, Mearns LO, Fu G. 2001. Regional climate information evaluation and projections, Climate Change: the scientific basis. Cambridge University Press. pp. 583-638.

Giorgi F, Coppola E, Solmon F, Mariotti L, Sylla MB, Bi X, Elguindi N, Diro GT, Nair V, Giuliani G, Cozzini S, Gu“ttler I, O’Brien TA, Tawfik AB, Shalaby A, Zakey AS, Steiner AL, Stordal F, Sloan LC, Brankovic C. 2012. RegCM4: model description and preliminary tests over multiple CORDEX domains. Clim. Res. 52: 7-29. 
Goodess CM, Anagnostopoulo C, Bardossy A, Frei C, Harpham C, Haylock MR, Hundecha Y, Maheras P, Ribalaygua J, Schmidli J, Schmith T, Tolika K, Tomozeiu R, Wilby RL. 2012. An intercomparison of statistical downscaling methods for Europe and European regions assessing their performance with respect to extreme temperature and precipitation events. Climatic Research Unit Research Publication (CRURP) N.11, University of East Anglia, UK. http://www.cru.uea.ac.uk/cru/pubs/crurp/CRU_RP11.pdf.

Kar SC. 2007. Global model simulations of interannual variability of the Indian summer monsoon using observed SST variability. NCMRWF research Report, NMRF/RR/2/2007; 40 pp.

Kar SC, Iyengar GR, Bohra AK. 2011. Ensemble spread and model systematic errors in the monsoon rainfall forecasts using the NCMRWF global ensemble prediction system. Atmosfera 24 (2): 173-191.

Kar SC, Rana S. 2013. Interannual variability of winter precipitation over northwest India and adjoining region: impact of global forcings. Theor. Appl. Climatol. 116: 609-623.

Kumar KK, Hoerling M, Rajagopalan B, 2005. Advancing dynamical prediction of Indian monsoon rainfall. Geo. Res. Lett. 32 L08704. doi:10.1029/2004GL021979.

Maraun D, Wetterhall F, Ireson AM, Chandler RE, Kendon EJ, Widmann M, Brienen S, Rust HW, Sauter T, Themel M, Venema VKC, Chun KP, Goodess CM, Jones RG, Onof C, Vrac M, Thiele-Eich I. 2010. Precipitation downscaling under climate change: recent developments to bridge the gap between dynamical models and the end user. Rev. Geophys. 48, DOI: 10.1029/2009RG000314.

Mohanty UC, Nageswararao MM, Sinha P, Nair A, Singh A, Rai RK, Kar SC, Ramesh KJ, Singh KK, Ghosh K, Rathore LS, Sharma R, Kumar A, Dhekale BS, Maurya RKS, Sahoo RK, 
Dash GP. 2018. Evaluation of performance of seasonal precipitation prediction at regional scale over India. Theo. and Appl. Climatol., https://doi.org/10.1007/s00704-018-2421-9].

Grigory N, Shakeel A, María M, Sandro C, Rita C, Jonas B, Jesús F, María F, Kristina F, Barbara F, Sixto G, Rodrigo M, José G, Ulf H, Michael K, Mark L, Pedro S, Christoph S, Ricardo T, Klaus W. 2018. Dynamical and statistical downscaling of a global seasonal hindcast in eastern Africa. Clim. Servi. 9: 72-85.

Pai DS, Sridhar L, Rajeevan M, Sreejith OP, Satbhai NS, Mukhopadhyay B. 2014. Development of a new high spatial resolution $\left(0.25^{\circ} \times 0.25^{\circ}\right)$ long period $(1901-2010)$ daily gridded rainfall data set over India and its comparison with existing data sets over the region. Mausam 65: 1-8.

Perez P, Reyes J. 2001. Prediction of particulate air pollution using neural techniques. Neural Computing and Application 10: 165-171.

Ramírez MC, N. J. Ferreira, and H. F. C. Velho, 2006: Linear and nonlinear statistical downscaling for rainfall forecasting over southeastern Brazil. Wea. Forecasting, 21, 969989.

Sachindra DA, Huang F, Barton AF, Perera BJC. 2012. Issues associated with statistical downscaling of general circulation model outputs: a discussion. In Proceedings of Practical Responses to Climate Change National Conference. Canberra, Australia, 1-3 May 2012.

Sachindra DA, Huang F, Barton A, Perera BJ. 2014a. Statistical downscaling of general circulation model outputs to precipitation-part 1: Calibration and validation. Int. J. Climatol. 34: 3264-3281. 
Sachindra DA, Huang F, Barton A, Perera BJ. 2014b. Statistical downscaling of general circulation model outputs to precipitation - part 2: bias-correction and future projections. Int. J. Climatol. 34: 3282-3303.

Saha S, Moorthi S, Wu X, Wang J, Nadiga S, Tripp P, Behringer D, HouY-T, Chuang H-y, Iredell M. 2014. The NCEP climate forecast system version 2. J. Clim. 27(6): 2185-2208.

Schmidli J, Goodess CM, Frei C, Haylock MR, Hundecha Y, Ribalaygua J, Schmith T. 2007. Statistical and dynamical downscaling of precipitation: An evaluation and comparison of scenarios for the European Alps. J. Geophys. Res. 112: D04105, doi: 10.1029/ 2005JD007026.

Shukla J. and Coauthors, 2000. Dynamical seasonal prediction. Bull. Amer. Meteor. Soc. 81: 2593-2606.

Singh A, Kulkarni MA, Mohanty UC, Kar SC, Robertson AW, Mishra G. 2012. Prediction of Indian summer monsoon rainfall (ISMR) using canonical correlation analysis of global circulation model products. Met. Appl. 19: 179-188.

Sinha P, Mohanty UC, Kar SC, Dash SK, Robertson A, Tippett M. 2013a. Seasonal Prediction of the Indian Summer Monsoon Rainfall using Canonical Correlation Analysis of the NCMRWF Global Model Products. Int. J. Clim. 33: 1601-1614.

Sinha P, UC Mohanty, SC Kar, SK Dash, Kumari S. 2013b. Sensitivity of the GCM driven summer monsoon simulations to cumulus parameterization schemes in nested RegCM3. Theo. and Appl. Climatol. 112 (1-2): 285-306.

Smith TM, Reynolds RW, Thomas CP, Lawrimore J. 2008. Improvements to NOAA's Historical Merged Land-Ocean Surface Temperature Analysis (1880-2006). J. Clim. 21: 2283-2296. 
Sorland SL, Schar C, Luthi D, Kjellström E. 2018. Bias patterns and climate change signals in GCM-RCM model chains. Environ. Res. Lett. 13:074017.

Su H, Xiong Z, Yan X, Dai X, Wei W. 2017. Comparison of monthly rainfall generated from dynamical and statistical downscaling methods: a case study of the Heihe River Basin in China. Theor. Appl. Climatol. 129: 437-444.

Taylor KE, Stouffer RJ, Meehl GA. An overview of CMIP5 and the experiment design. 2012. Bull. Am. Meteor. Soc. 9: 485-498.

Tiwari PR, Kar SC, Mohanty UC, Kumari S, Sinha P, Nair A, Dey S. 2014. Skill of precipitation prediction with GCMs over north India during winter seasons. Int. J. Climatol. 34: 34403455.

Tiwari PR, Kar SC, Mohanty UC, Dey S, Kumari S, Sinha P. 2016a. Seasonal prediction skill of winter temperature over North India. Theo. and Appl. Climatol. 124 (1-2): 15-29.

Tiwari PR, Kar SC, Mohanty UC, Dey S, Sinha P, Raju PVS, Shekhar MS. 2016b. On the dynamical downscaling and bias correction of seasonal-scale winter precipitation predictions over North India. Q. J. R. Meteorol. Soc. 142: 2398-2410.

Tiwari PR, Kar SC, Mohanty UC, Dey S, Sinha P, Shekhar MS. 2017. Sensitivity of the Himalayan orography representation in simulation of winter precipitation using Regional Climate Model (RegCM) nested in a GCM. Clim. Dyn. doi:10.1007/s00382-017-3567-3.

Trigo RM, Palutikof JP. 2001. Precipitation scenarios over Iberia: A comparison between direct GCM output and different downscaling techniques. J. Clim.14: 4422-4446,

Wang B, Ding Q, Fu X, Kang I-S, Jin K, Shukla J, Doblas-Reyes F. 2005. Fundamental challenge in simulation and prediction of summer monsoon rainfall. Geophys. Res. Lett. 32: L15711, doi:10.1029/2005GL022734. 
Wang B, Lee JY, Kang IS, Shukla J, Park CK, Kumar A, Schemm J, Cocke S, Kug JS, Luo JJ, Zhou T, Wang B, Fu X, Yun WT, Alves O, Jin EK, Kinter J, Kirtman B, Krishnamurti TN, Lau N, Lau W, Liu P, Pegion P, Rosati T, Schubert S, Stern W, Suarez M, Yamagata T. 2009. Advance and prospectus of seasonal prediction: assessment of the APCC/CliPAS 14model ensemble retrospective seasonal prediction (1980-2004). Clim. Dyn. 33: 93-117.

Wilby RL, Charles SP, Zorita E, Timbal B, Whetton P, Mearns LO. 2004. Guidelines for use of climate scenarios developed from statistical downscaling methods. Tech. Report, Data Distribution Centre of the IPCC.

Wilks DS. 1995. Statistical Methods in the Atmospheric Sciences. Academic Press: San Diego, $C A ; 467$ pp.

Wilks DS. 2006. Statistical methods in atmospheric sciences. Elsevier Inc. Second Edition.

Willmott CJ. 1982. Some comments on the evaluation of model performance. Bull. Am. Meteorol. Soc. 63: $1309-1313$. 


\section{List of Figures}

Figure 1. Hovmoller diagram (longitudinal mean) of precipitation (in $\mathrm{mm} /$ day) of each year form (a) observation (b) T80 model simulations and (c) bias.

Figure 2. Spatial average of DJF precipitation anomaly over NI for observed (black line) and model simulations (red line denotes ensemble mean, red closed diamonds denote individual ensemble members respectively).

Figure 3.Statistical analysis between observed and T80 model DJF precipitation (model precipitation is interpolated in observed grid) for the period 1982-2007 shown (a) for Correlation Coefficient and (b) for normalized mean squared error ( $\mathrm{mm} /$ day).

Figure 4. Anomaly correlation between wintertime (DJF) precipitation over NI and different meteorological parameters (surface as well as upper air) obtained from the observation vs T80 model output for the period 1982-2007. Only values significant at the 95\% level are plotted.

Figure 5. Spatial domains of various predictors used in MOS approaches.

Figure 6. Anomaly correlation coefficient skill of Model Output Statistics (MOS)-corrected hindcasts (1982-2006) using various T80 model predictors over the three domains in Fig. 5: (a) precipitation, domain 1; (b) meridional wind at $200 \mathrm{hPa}$, domain 1; (c) zonal wind at $850 \mathrm{hPa}$, domain 2 ; (d) meridional wind at $850 \mathrm{hPa}$, domain 2 (e) zonal wind at $200 \mathrm{hPa}$, domain 2 (f) temperature at $200 \mathrm{hPa}$, domain 2; (g) zonal wind at $850 \mathrm{hPa}$, domain 3; (h) zonal wind at $200 \mathrm{hPa}$, domain 3; (i) composite of all predictors forecast. 
Figure 7. Prediction yields for T80, bias corrected T80 (T80_MBR \& T80_QM), CCA, bias corrected CCA (CCA_MBR \& CCA_QM), RegCM and bias corrected RegCM (RegCM_MBR \& RegCM_QM) for different categories of percentage error.

Figure 8. Area average precipitation percentage departure (\%) for T80 (in grey bars), QM based bias correction method applied on T80 (T80_QM, in cyan bar), CCA based statistical downscaling (in coral bars), QM based bias correction method applied on CCA (CCA_QM, in dark orchid bar), dynamical downscaling based RegCM (RCM, in skyblue bar), QM based bias corrected method for downscaled RCM (in green bars) and the observed departure (in black bars) for years (a) 2008 and (b) 2009 respectively. 


\section{List of Tables}

Table 1. Skill scores of the T80, bias corrected T80 (T80_MBR \& T80_QM), CCA, bias corrected CCA (CCA_MBR \& CCA_QM), RegCM and bias corrected RegCM (RegCM_MBR \& RegCM_QM) during 1982-2007.

Table 2. Seasonal mean precipitation over seventeen (17) stations obtained from SASE observation, T80, CCA based statistical downscaling, T80 driven RegCM (RCM) and bias corrected RegCM (QM) for composite wet minus dry years. The shaded values are closer to the observations. The model data is bi-linearly interpolated to the station locations. 
Table 1. Skill scores of the T80, bias corrected T80 (T80_MBR \& T80_QM), CCA, bias corrected CCA (CCA_MBR \& CCA_QM), RegCM and bias corrected RegCM (RegCM_MBR \& RegCM_QM) during 1982-2007.

\begin{tabular}{|l|l|l|l|l|l|l|l|l|l|}
\hline \begin{tabular}{|l} 
Skill \\
$\begin{array}{l}\text { Metric } \\
\text { s }\end{array}$
\end{tabular} & T80 & T80_MBR & T80_QM & CCA & $\begin{array}{l}\text { CCA_ } \\
\text { MBR }\end{array}$ & $\begin{array}{l}\text { CCA_Q } \\
\text { M }\end{array}$ & RegCM & $\begin{array}{l}\text { RegCM_M } \\
\text { BR }\end{array}$ & $\begin{array}{l}\text { RegCM_Q } \\
\text { M }\end{array}$ \\
\hline $\begin{array}{l}\text { Muiltipl } \\
\text { icative } \\
\text { Bias }\end{array}$ & 0.49 & 0.51 & 0.54 & 0.67 & 0.69 & 0.76 & 0.58 & 0.72 & 0.81 \\
\hline $\begin{array}{l}\text { Kendal } \\
\text { l's tau }\end{array}$ & 0.21 & 0.24 & 0.29 & 0.33 & 0.36 & 0.41 & 0.30 & 0.37 & 0.45 \\
\hline \begin{tabular}{l} 
WIOA \\
\hline
\end{tabular} & 0.36 & 0.39 & 0.44 & 0.55 & 0.57 & 0.63 & 0.51 & 0.64 & 0.76 \\
\hline
\end{tabular}


Table 2. Seasonal mean precipitation over seventeen (17) stations obtained from SASE observation, T80, CCA based statistical downscaling, T80 driven $\operatorname{RegCM}(\mathrm{RegCM})$ and bias corrected $\operatorname{RegCM}(\mathrm{QM})$ for composite wet minus dry years. The shaded values are closer to the observations. The model data is bi-linearly interpolated to the station locations.

\begin{tabular}{|l|c|c|c|c|c|}
\hline \multirow{2}{*}{ Station } & \multicolumn{5}{|c|}{ Composite (wet minus dry) } \\
\cline { 2 - 6 } & SASE & T80 & CCA & RegCM & RegCM_QM \\
\hline 1. Bahadur & $\mathbf{1 . 4 1}$ & 1.76 & 1.32 & -0.33 & 1.35 \\
\hline 2. Banihal & $\mathbf{4 . 7 0}$ & 3.11 & 3.58 & 4.42 & 2.31 \\
\hline 3. Bhang & $\mathbf{2 . 0 8}$ & -0.51 & 1.91 & 3.62 & 0.97 \\
\hline 4. Dhundi & $\mathbf{2 . 5 3}$ & -0.23 & 2.96 & 4.05 & 2.91 \\
\hline 5. Dras & $\mathbf{5 . 0 6}$ & 2.21 & 4.63 & 5.30 & 5.81 \\
\hline 6. Gulmarg & $\mathbf{3 . 1 4}$ & -0.33 & 2.81 & 3.23 & 3.19 \\
\hline 7. H-Taj & $\mathbf{5 . 6 1}$ & 3.05 & 5.92 & 6.37 & 5.63 \\
\hline 8.Kanzalwan & $\mathbf{6 . 0 5}$ & 2.91 & 6.25 & 4.12 & 6.16 \\
\hline 9. Kumar & $\mathbf{1 . 4 6}$ & 1.41 & 4.75 & 2.73 & 2.18 \\
\hline 10. Neeru & $\mathbf{2 . 3 2}$ & 1.84 & 2.26 & -1.38 & 2.25 \\
\hline 11. Patsio & $\mathbf{1 . 5 8}$ & -0.07 & 1.45 & -0.41 & 1.47 \\
\hline 12. Pharki & $\mathbf{4 . 3 2}$ & 1.41 & 3.83 & 4.73 & 4.24 \\
\hline 13. Solang & $\mathbf{5 . 3 1}$ & 3.31 & 5.27 & 4.29 & 3.91 \\
\hline 14. Stg-II & $\mathbf{6 . 8 3}$ & 3.61 & 4.58 & 3.52 & 6.54 \\
\hline 15. Z-Gali & $\mathbf{3 . 3 1}$ & -0.23 & 3.85 & 4.63 & 3.27 \\
\hline 16. Gugaldhar & $\mathbf{3 . 5 2}$ & -0.16 & -0.50 & -0.49 & -0.48 \\
\hline 17. Dawar & $\mathbf{1 . 7 1}$ & -0.17 & -0.06 & -0.32 & 1.74 \\
\hline
\end{tabular}



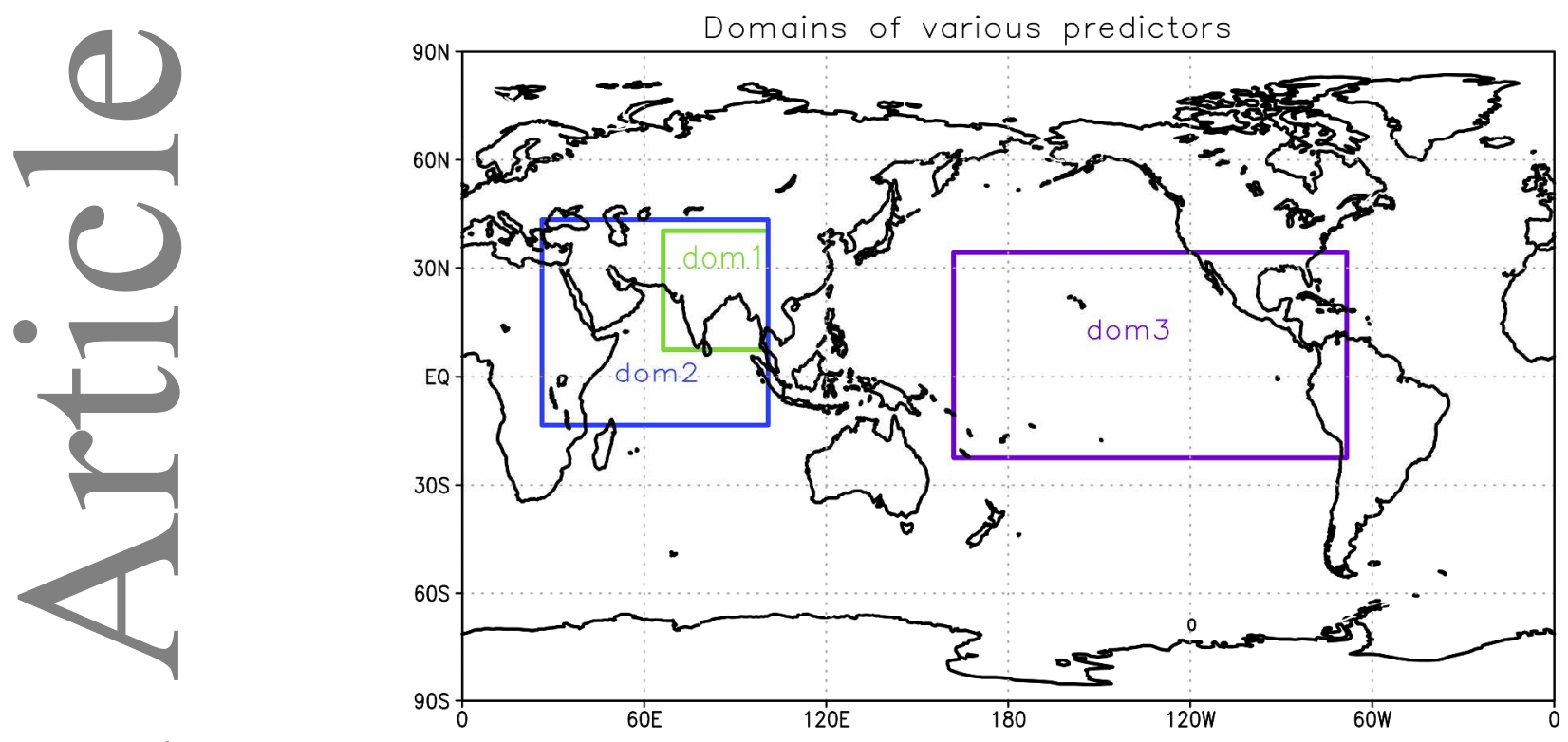

Figure 5. Spatial domains of various predictors used in the MOS approache. $279 \times 215 \mathrm{~mm}(300 \times 300 \mathrm{DPI})$ 


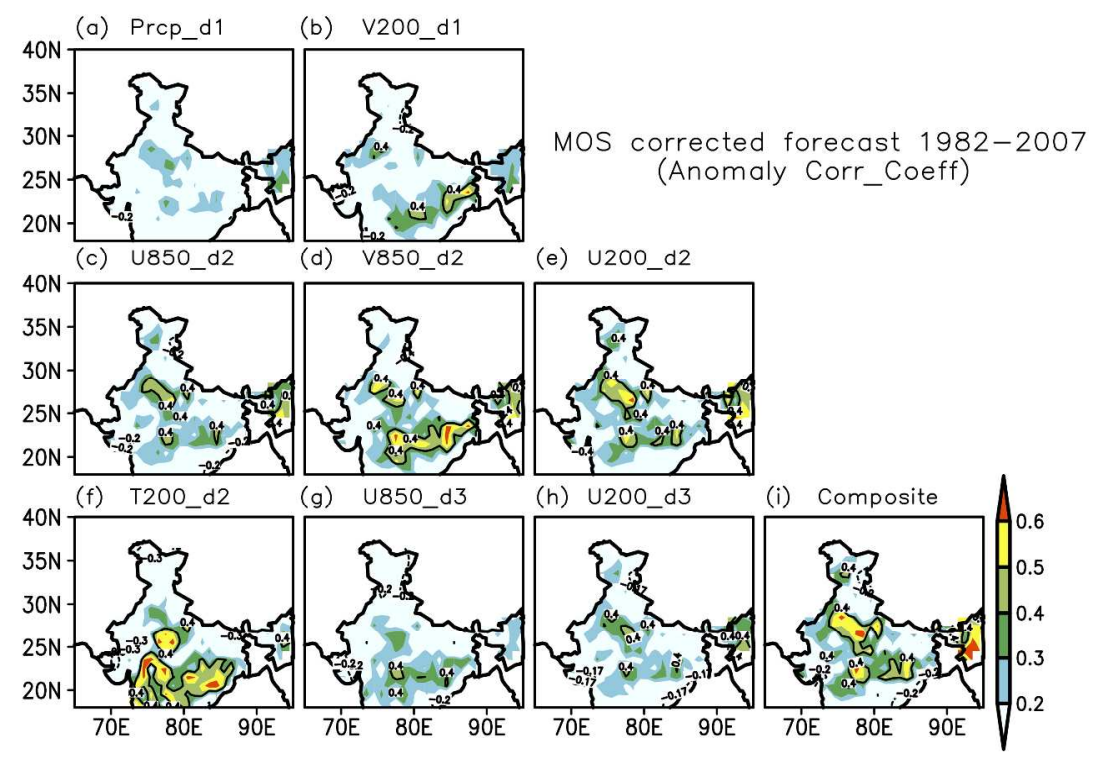

Figure 6. Anomaly correlation coefficient skill of Model Output Statistics (MOS)-corrected hindcasts (19822006) using various T80 model predictors over the three domains in Fig. 5: (a) precipitation, domain 1; (b) meridional wind at $200 \mathrm{hPa}$, domain 1; (c) zonal wind at $850 \mathrm{hPa}$, domain 2; (d) meridional wind at 850 $\mathrm{hPa}$, domain 2 (e) zonal wind at $200 \mathrm{hPa}$, domain 2 (f) temperature at $200 \mathrm{hPa}$, domain 2; (g) zonal wind at $850 \mathrm{hPa}$, domain 3; (h) zonal wind at $200 \mathrm{hPa}$, domain 3; (i) composite of all predictors forecast. 


\section{Percentage yield for different categories of percentage error}

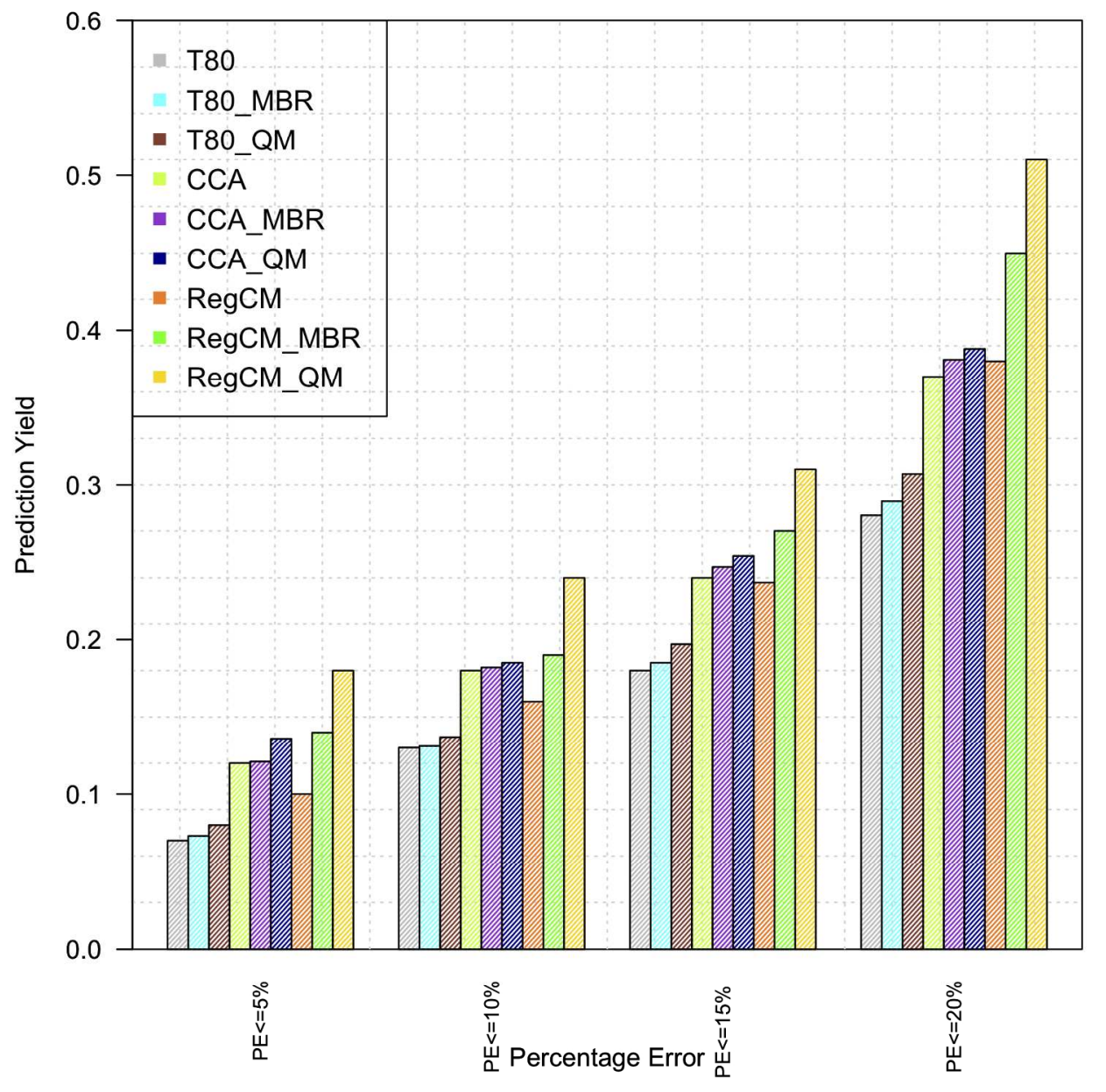

Figure 7. Prediction yields for T80, bias corrected T80 (T80_MBR \& T80_QM), CCA, bias corrected CCA (CCA_MBR \& CCA_QM), RegCM and bias corrected RegCM (RegCM_MBR \& RegCM_QM) for different categories of percentage error.

$187 \times 199 \mathrm{~mm}(300 \times 300 \mathrm{DPI})$ 


\section{$\%$ departure for the year $2008 \& 2009$}
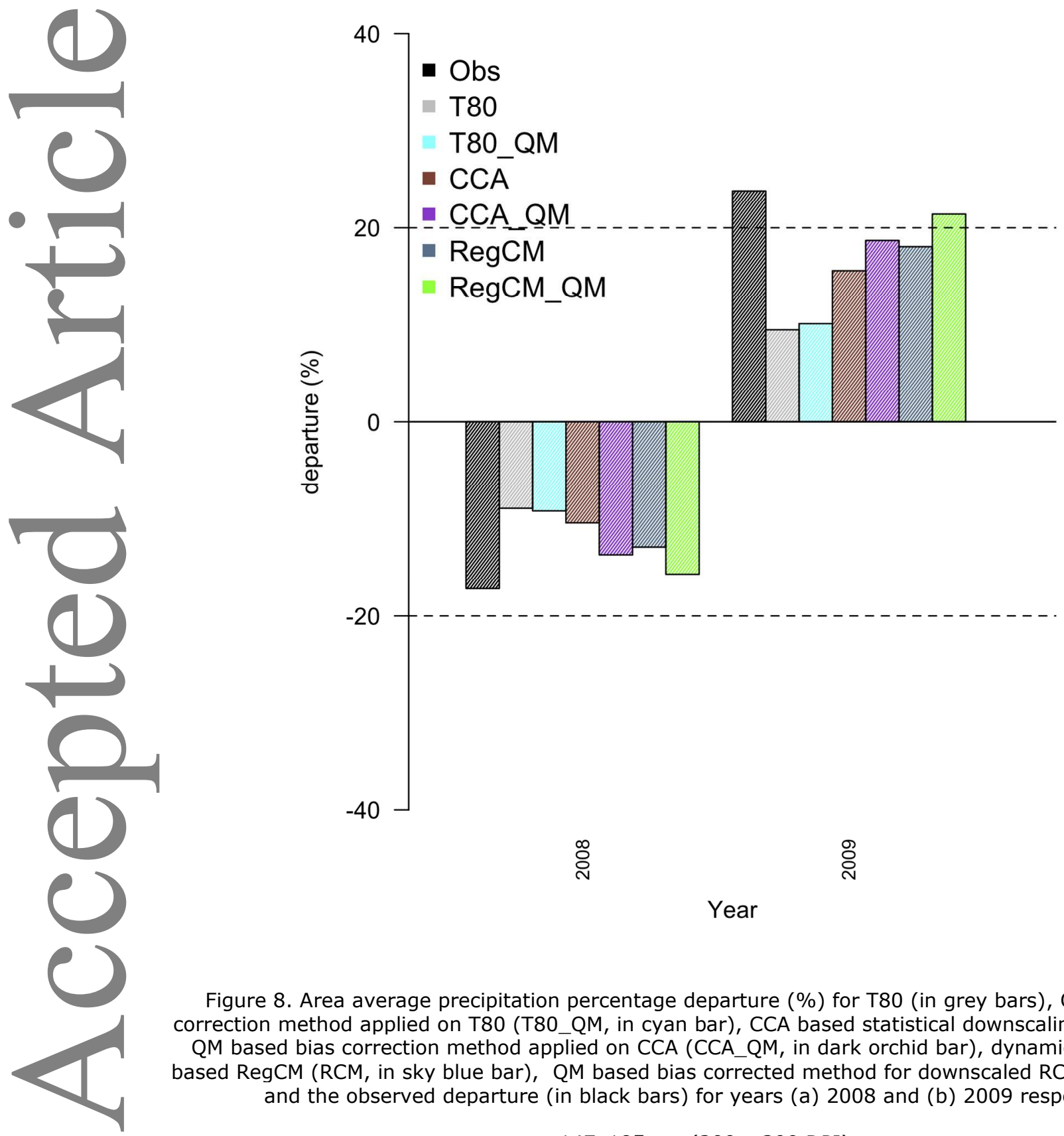

Figure 8. Area average precipitation percentage departure (\%) for T80 (in grey bars), QM based bias correction method applied on T80 (T80_QM, in cyan bar), CCA based statistical downscaling (in coral bars), QM based bias correction method applied on CCA (CCA_QM, in dark orchid bar), dynamical downscaling based RegCM (RCM, in sky blue bar), QM based bias corrected method for downscaled RCM (in green bars) and the observed departure (in black bars) for years (a) 2008 and (b) 2009 respectively.

$147 \times 185 \mathrm{~mm}(300 \times 300$ DPI $)$ 